\title{
Relationship of the Distribution Thickness of Dielectric Layer on the Nano-Tip Apex and Distribution of Emitted Electrons
}

\author{
Ala'a M. Al-Qudah, Marwan S. Mousa* \\ Department of Physics, Mu'tah University, Al-Karak 6170, Jordan
}

*Correspondence to:
Mousa MS,
Tel: +962-79-565-9761
Fax: +962-3-2375540
E-mail: marwansmousa@yahoo.com,
$\quad$ mmousa@mutah.edu.jo

Received July 18, 2016

Revised September 13, 2016

Accepted September 13, 2016

\begin{abstract}
This paper analyses the relationship between the distribution of a dielectric layer on the apex of a metal field electron emitter and the distribution of electron emission. Emitters were prepared by coating a tungsten emitter with a layer of epoxylite resin. A highresolution scanning electron microscope was used to monitor the emitter profile and measure the coating thickness. Field electron microscope studies of the emission current distribution from these composite emitters (Tungsten-Clark Electromedical Instruments Epoxylite resin [Tungsten/CEI-resin emitter]) have been carried out. Two forms of image have been observed: bright single-spot images, thought to be associated with a smooth substrate and a uniform dielectric layer; and multi-spot images, though to be associated with irregularity in the substrate or the dielectric layer.
\end{abstract}

Key Words: Field electron emitter, Dielectric layer, Composite emitter, Field electron

microscope, Scanning electron microscope

\section{INTRODUCTION}

Field electron emission is the emission of electrons from the surface of a cathode under the influence of a high applied electrostatic field (typically about $3 \mathrm{~V} / \mathrm{nm}$ ) (Forbes et al., 2004; Mousa, 1996). The field electron emitter is particularly attractive as an electron source, due to its suitable emission properties and simple operating principle (Fischer et al., 2013). Tungsten is still one of the materials that are most frequently used for manufacturing field emitter tips (Latham, 1981; Marrese, 2000; Marulanda, 2010).

Theoretically, cold field electron emission is the regime where (i) the electrons in the emitting region are effectively in local thermodynamic equilibrium (Mousa et al., 2012), and (ii) most electrons escape by deep tunneling from states close to the emitter's Fermi level (Forbes et al., 2013). The first scientist to attempt to develop theory for cold field emission was Schottky (1923). Fowler and Nordheim (1928) developed the first appropriate theory for explaining field emission related phenomena. The first observation of what appears to be a field electron emission initiated electric discharge had been made by Winkler long before (Winkler \& Gedanken, 1744).

Electron emitter fabrication technology based on electrolytic etching (Melmed, 1991) has long been investigated and enhanced. This technology makes it possible to prepare electron emitters with a diameter in the nanometre range (Golubev \& Shrednik, 2003). A wide range of composite micropoint cathodes has been manufactured in the authors' group. The role of epoxylite resin in manufacturing composite emitters (Tungsten-Clark Electromedical Instruments Epoxylite resin [Tungsten/CEI-resin emitter]) have been to avoid degradation of the electron emitter tip due to ion sputtering processes during emission, to obtain an electron emitter with long lifetime, and improve the emission characteristics for the emitter (Mousa \& Share, 1999; Mousa et al., 2001, 2012).

In this work, various composite microemitters (Tungsten/ CEI-resin emitter) with different apex radii ranging from 112 to $287 \mathrm{~nm}$ were prepared. Scanning electron microscope (SEM) images were used to extract tip profiles (i.e., apex

(a) This is an open-access article distributed under the terms of the Creative Commons Attribution Non-Commercial License (http://creativecommons.org/licenses/by-nc/4.0) which permits unrestricted noncommercial use, distribution, and reproduction in any medium, provided the original work is properly cited.

Copyrights @ 2016 by Korean Society of Microscopy 
radii) and emission images were photographed directly from the phosphor screen of a field electron microscope (FEM), using a digital camera.

\section{MATERIALS AND METHODS}

The tungsten emitter used here were electrolytically etched from $0.1 \mathrm{~mm}$ high purity $(99.95 \%)$ tungsten wires (produced by Good fellow Metals Company) using a $2 \mathrm{M}$ solution of sodium hydroxide $(\mathrm{NaOH})$. The tip (anode) and the carbon rod (cathode) were connected to a power supply that provides the bias voltage necessary to generate the etching current. In our case, $10 \sim 12 \mathrm{~V}$ were used. The micro-ammeter monitors the current between the anode and the cathode, in order to quickly switch off the voltage when the etching is completed. The latter point is extremely important, as the cut-off time of the etching circuit greatly affects the sharpness of the tip. The etched sample was then cleaned from any remains of the $\mathrm{NaOH}$ solution on the surface of the tip by being immersed in distilled water and subjected to an ultrasonic bath for some minutes (Al-Qudah et al., 2015; Madanat et al., 2015). The setup used for etching our W tips is shown in Fig. 1.

Coating the emitters with epoxylite resin (Clark Electromedical Instruments, CEI-resin) involves two steps. First, a tip is dipped into the resin very slowly, in the following way. A sample holder that keeps samples vertical is mounted on a trolley that moves vertically and lowers/withdraws the sample into/from a flask of epoxylite resin, whilst keeping the $90^{\circ}$ angle between the surface of epoxylite resin and the tip. Second, the coated emitters are carefully transferred to an oven, and subjected to a curing cycle of thirty minutes at $100^{\circ} \mathrm{C}$ to drive off the solvents, followed by another thirty minutes at $185^{\circ} \mathrm{C}$ to complete the curing of the resin ( $\mathrm{Al}-$ Qudah et al., 2015; Latham \& Mousa,1986). The composite emitter is then mounted in a standard FEM with an emitterscreen distance of $10 \mathrm{~mm}$ (Alnawasreh et al., 2015; Latham \&

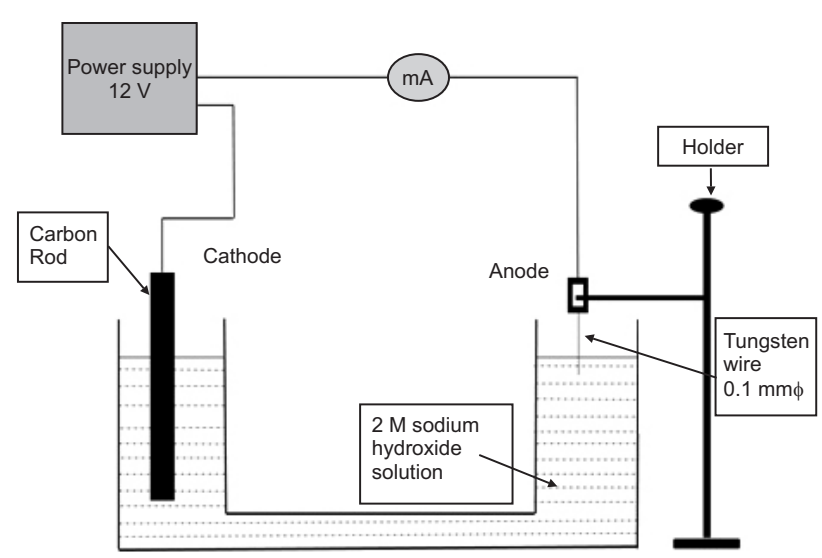

Fig. 1. Electrolytic etching system.
Salim, 1987; Meza et al., 2015).

The emission images were photographed directly from a phosphor screen coated by tin-oxide layers. All experiments were performed under pressures $\sim 10^{-8}$ mbar, obtained by baking the ultra-high vacuum system to $\sim 200^{\circ} \mathrm{C}$ for 12 hours. An oil diffusion pump system was used, connected to a liquid nitrogen $\left(\mathrm{LN}_{2}\right)$ trap, as shown in Fig. 2. The radius of each emitter apex was measured from images taken in a $20 \mathrm{kV}$ SEM, at magnifications up to $\sim 30,000 \times$.

\section{RESULTS AND DISCUSSION}

The composite microemitters (Tungsten/CEI-resin emitters) that were prepared have various apex radii, ranging from 112 to $287 \mathrm{~nm}$. The presented results include SEM (FEI Company, 2010; Hitachi S-4700 SEM, 2007; Mousa, 2007) and FEM images taken by digital camera.

Fig. 3 presents a SEM image for emitter 1 which has an approximately hemispherical apex, with a measured radius $r_{\mathrm{SEM}}$ of $158 \mathrm{~nm}$ and a resin-layer thickness $t_{\mathrm{SEM}}$ of $30 \mathrm{~nm}$. The resin layer was uniformly distributed on the emitter apex. The FEM image primarily consists of a single bright spot, as shown in Fig. 4. The SEM image for emitter 2 (Fig. 5) has an approximately hemispherical apex with $r_{\mathrm{SEM}}=116 \mathrm{~nm}$ and $t_{\mathrm{SEM}}=53 \mathrm{~nm}$. The resin layer was uniformly distributed on the emitter apex. The FEM image (Fig. 6) again consists of a single bright spot.

Emitter 3 has an approximately hemispherical apex, with $r_{\mathrm{SEM}}=112 \mathrm{~nm}$ and $t_{\mathrm{SEM}}=35 \mathrm{~nm}$. Fig. 7 shows a SEM image. The FEM image (Fig. 8) again consists of a single bright spot. Note that all of the above emitters have a homogeneous distribution of the apex resin layer and generate FEM images with a single bright spot.

Emitter 4 has radius $r_{\mathrm{SEM}}=141 \mathrm{~nm}$ and $t_{\mathrm{SEM}}=21 \mathrm{~nm}$. Fig. 9

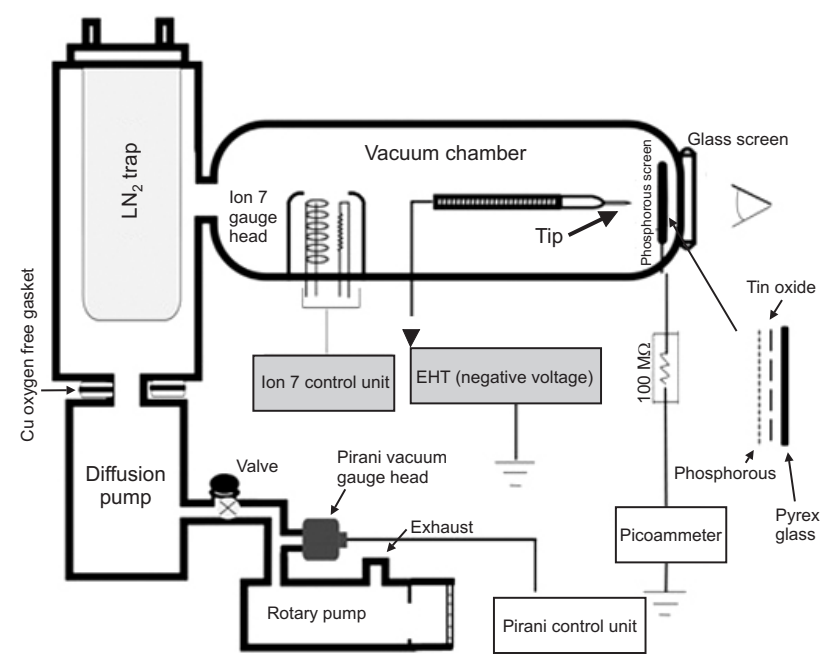

Fig. 2. Schematic diagram of the ultra-high vacuum system. 


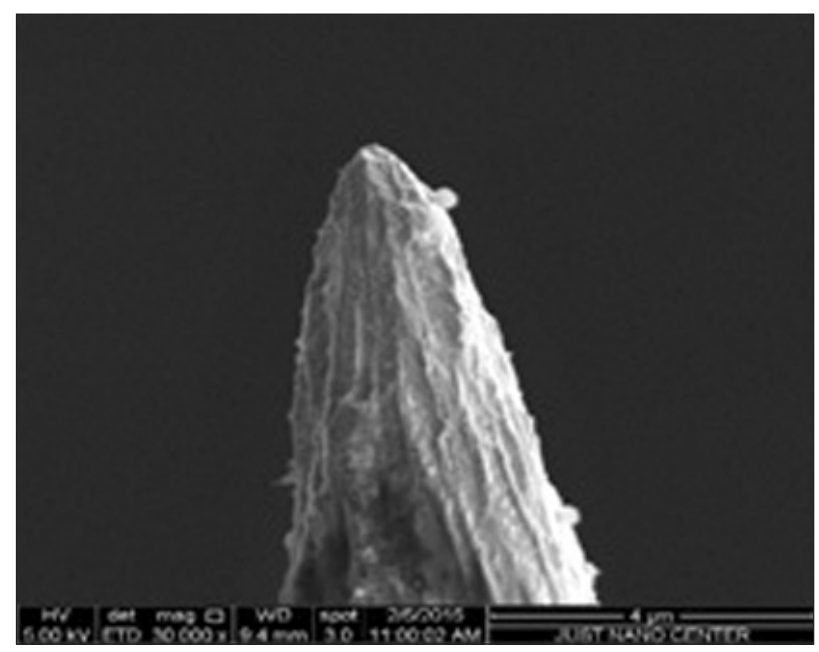

Fig. 3. SEM image for emitter 1 at magnification $(\times 30,000)$.
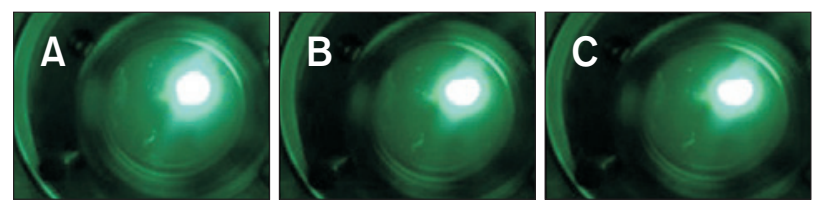

Fig. 4. FEM image structure for emitter 1 , at emission current $1.5 \mu \mathrm{A}$, and applied voltages: (A) 2,400 V, (B) 2,300 V, (C) 2,200 V. Time separation between consecutive images is 15 minutes.

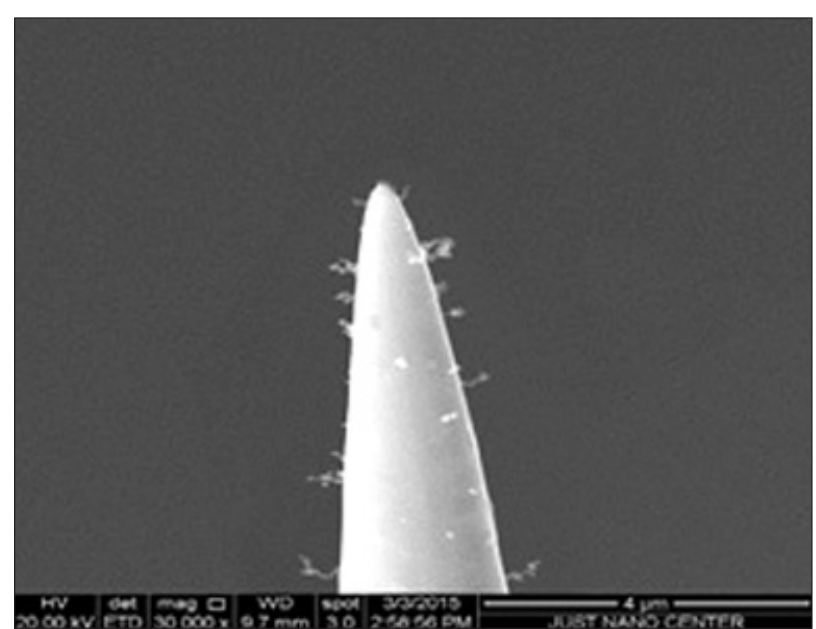

Fig. 5. SEM image for emitter 2 at magnification $(\times 30,000)$.
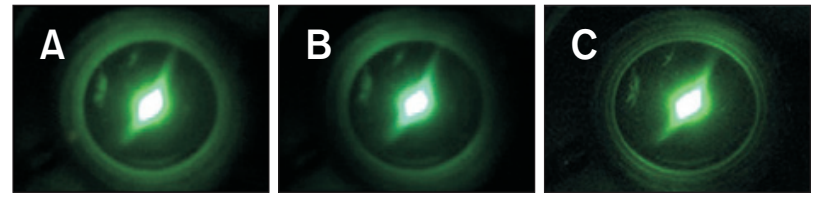

Fig. 6. FEM image structure for emitter 2 , at emission current $1.5 \mu \mathrm{A}$, and applied voltages: (A) $1,500 \mathrm{~V}$, (B) 1,400 V, (C) 1,300 V. Time separation between consecutive images is 15 minutes.

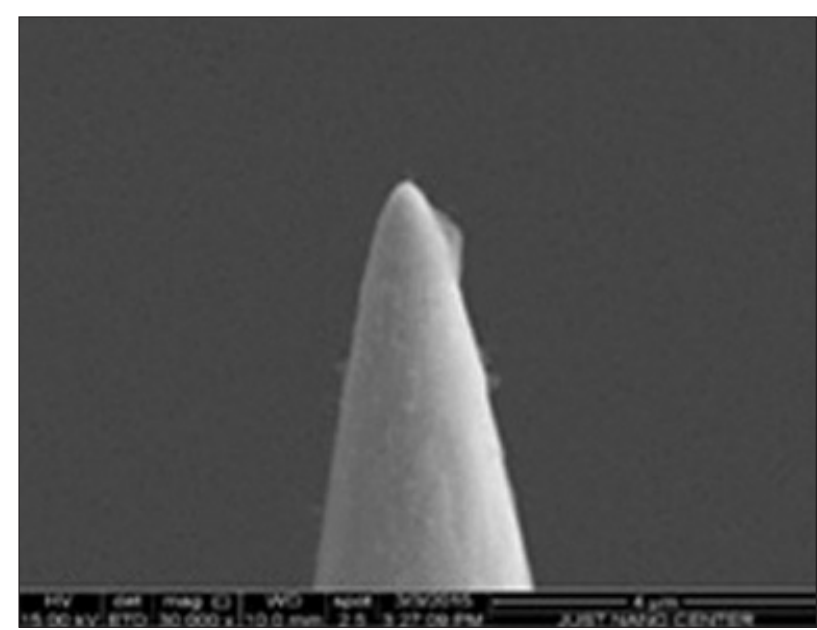

Fig. 7. SEM image for emitter 3 at magnification $(\times 30,000)$.
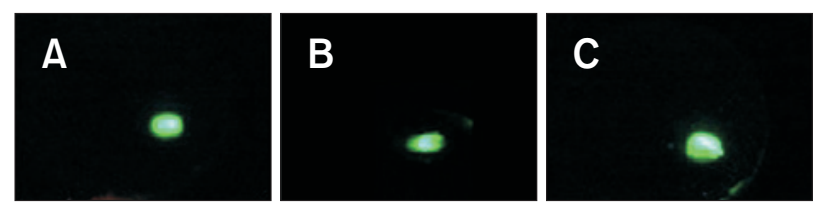

Fig. 8. FEM image structure for emitter 3 , at emission current $1.4 \mu \mathrm{A}$, and applied voltages: (A) 1,500 V, (B) 1,400 V, (C) 1,300 V. Time separation between consecutive images is 15 minutes.

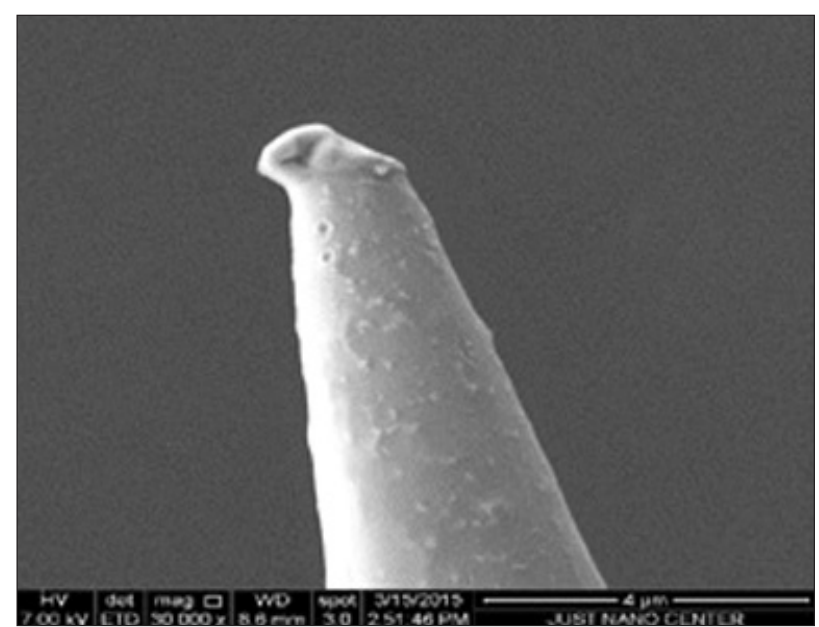

Fig. 9. SEM image for emitter4 at magnification $(\times 30,000)$.
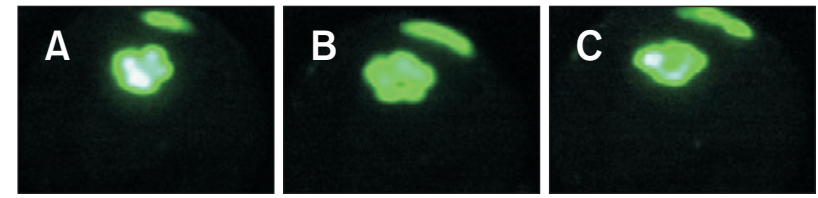

Fig. 10. FEM image structure for emitter 4: (A) $8 \mu \mathrm{A}$ at 2,500 V; (B) $7.4 \mu \mathrm{A}$ at 2,400 V; (C) $6.8 \mu \mathrm{A}$ at 2,300 V. Time separation between consecutive images is 15 minutes. 


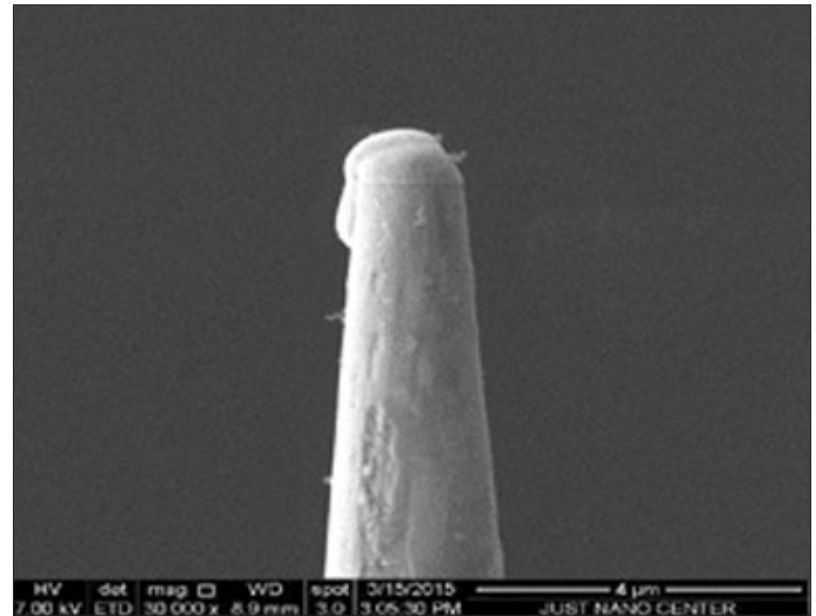

Fig. 11. SEM image for emitter 5 at magnification $(\times 30,000)$.
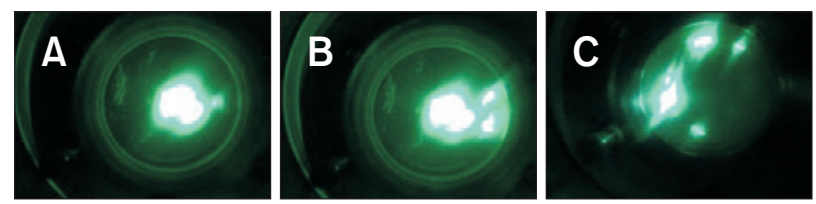

Fig. 12. FEM image structure for emitter 5 : (A) $1.5 \mu \mathrm{A}$ at $9,700 \mathrm{~V}$; (B) 6.8 $\mu \mathrm{A}$ at $9,600 \mathrm{~V}$; (C) $6.8 \mu \mathrm{A}$ at $9,300 \mathrm{~V}$. Time separation between consecutive images is 15 minutes.

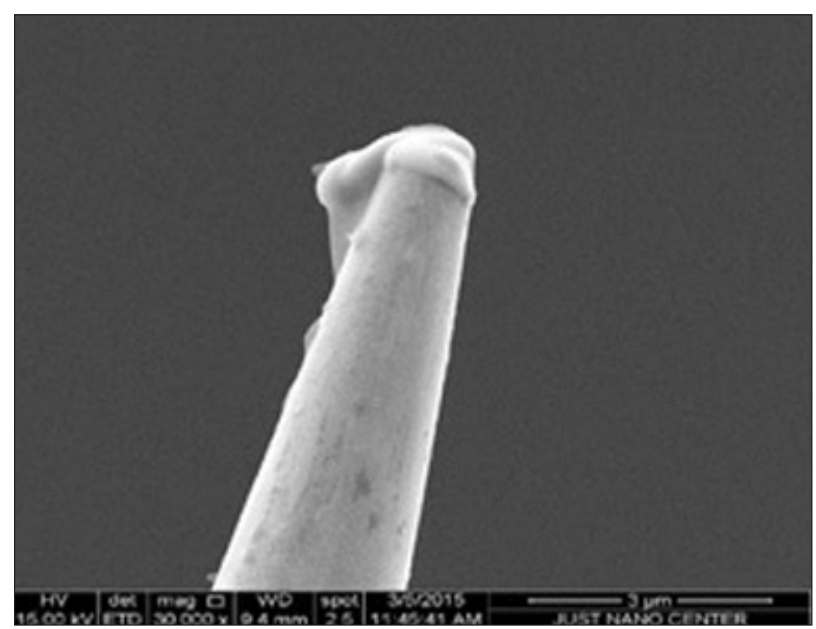

Fig. 13. SEM image for emitter 6 at magnification $(\times 30,000)$.
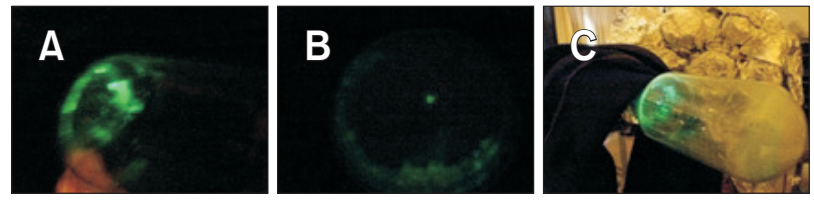

Fig. 14. FEM image structure for emitter 6: (A) $8.4 \mu \mathrm{A}$ at 9,000 V; (B) 8.1 $\mu \mathrm{A}$ at $8,900 \mathrm{~V}$; (C) $8.2 \mu \mathrm{A}$ at $8,800 \mathrm{~V}$. Time separation between consecutive images is 15 minutes. shows a SEM image. The FEM image (Fig. 10) shows multiple spots. Emitter 5 has radius $r_{\mathrm{SEM}}=287 \mathrm{~nm}$ and $t_{\mathrm{SEM}}=196 \mathrm{~nm}$. Fig. 11 shows a SEM image. The FEM image (Fig. 12) again shows multiple spots. Emitter 6 has radius $r_{\mathrm{SEM}}=219 \mathrm{~nm}$ and $t_{\text {SEM }}=135 \mathrm{~nm}$. Fig. 13 shows a SEM image. The FEM image (Fig. 14) again shows multiple spots.

The FEM images of the composite emitters studied in this work divide into two classes: (1) images consisting of a single bright spot; (2) images containing multiple spots.

The single-spot images appear to be associated with uniform distribution of the resin layer on the emitter apex, and are thought to be associated with the formation of a "conducting channel" through the resin, as illustrated schematically in

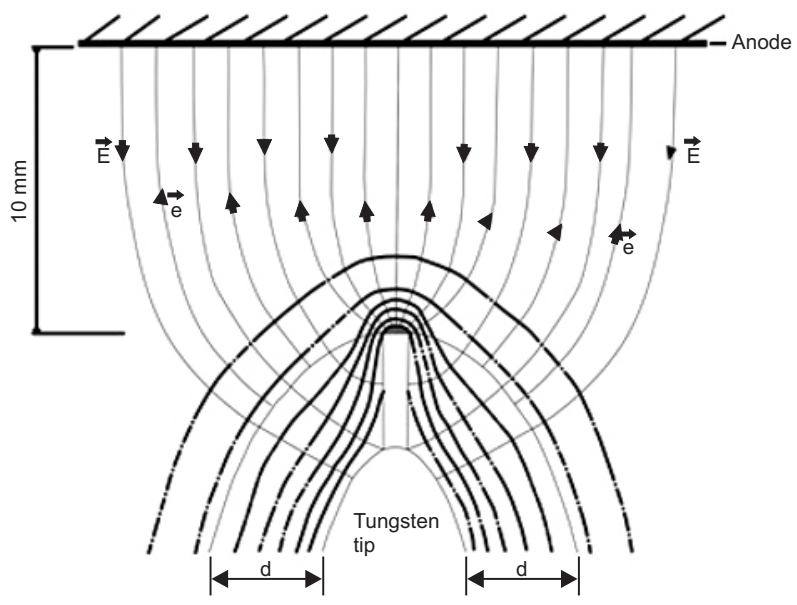

Fig. 15. Schematic representation of an emitting channel formed in the dielectric layer.

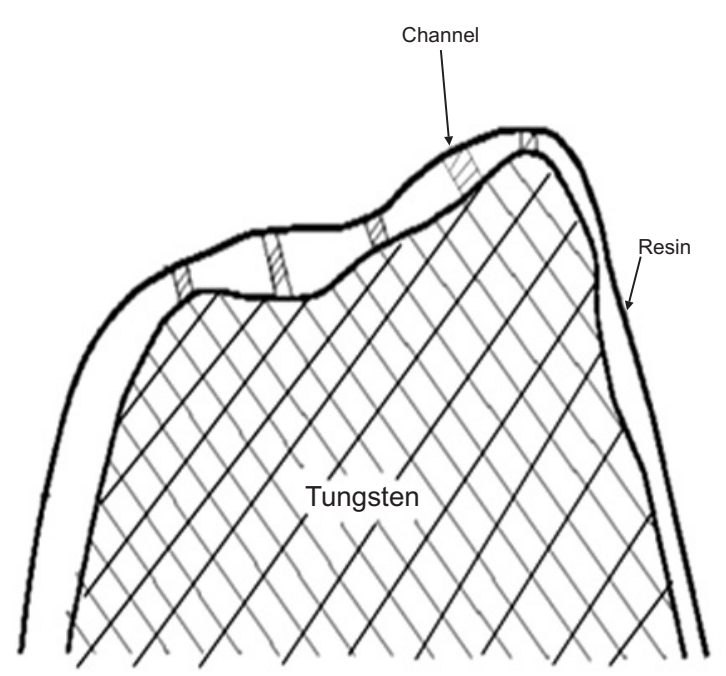

Fig. 16. Schematic illustration of how the irregularities of the substrate tungsten emitter could lead to a non-uniform surface film and formation of more than one channel. 
Fig. 15. The multi-spot FEM images appear to be associated with an inhomogeneous resin-layer distribution and/or with substrate irregularities that could give rise to the formation of multiple emitting channels, as illustrated schematically in Fig. 16. The experimental conclusion is that the combination of a smooth emitter and a uniform resin layer generates a single bright emission spot. This makes these emitters interesting as potential electron sources. But there remains work to be done to confirm that the emission mechanism does indeed involve the formation of a conducting channel (or filament).

\section{CONCLUSIONS}

It can be concluded that an electron source producing a single bright field emission spot has been produced employing a combination of a smooth emitter tip apex and a uniform epoxylite resin controlled layer such behavior makes these emitters interesting as potential electron sources. The physics of this behavior can be explained in the context of forming a conductive semi crystalized channel between the tip apex and the resin/vacuum surface. This channel will act as a conductive medium but well protect the core emitting tip from ion back bombardment which normally damages this emitting tip after sometime.

\section{CONFLICT OF INTEREST}

No potential conflict of interest relevant to this article was reported.

\section{ACKNOWLEDGMENTS}

Ala'a M. AL-Qudah would like to express gratitude to the Scientific Research Support Fund in the Hashemite Kingdom of Jordan for financial support enabled that in completing this Research works.

\section{REFERENCES}

Alnawasreh S, Mousa M S, and Al-Rabadi A N (2015) Investigating the effects of sample conditioning on nano-apex carbon fiber tips for efficient field electron emission. Jo. J. Phys. 8, 95-101.

Al-Qudah A M, Mousa M S, and Fischer A (2015) Effect of insulating layer on the Field Electron Emission Performance of Nano-Apex Metallic Emitters. IOP Conf. Ser. Mater. Sci. Eng. 92, 012021.

FEI Company (2010) Introduction to Electron Microscope.

Fischer A, Mousa M S, and Forbes R G (2013) Influence of barrier form on the extraction of information from Fowler-Nordheim plots. J. Vac. Sci. Technol. B 31, 032201.

Forbes R G, Deane J H, Hamid N, and Sim H S (2004) Extraction of emission area from Fowler-Nordheim plots. J. Vac. Sci. Technol. B 22 1222-1226.

Forbes R G, Fischer A, and Mousa M S (2013) Improved approach to Fowler-Nordheim plot analysis. J. Vac. Sci. Technol. B 31, 02B103, $1-8$.

Golubev O L and Shrednik V N (2003) Heat-field treatment of tips made of tungsten-hafnium alloy. Tech. Phys. 48, 776-779.

Hitachi S-4700 SEM (2007) Training and Reference Guide.

Latham R V (1981) High Voltage and Vacuum Insulation: The Physical Basis (Academic, London).

Latham R V and Mousa M S (1986). Hot electron emission from composite metal-insulator micropoint cathodes. J. Phys. D: Appl. Phys. 19, 699-713.

Latham R V and Salim M A (1987) A microfocus cathode ray tube using an externally stabilized carbon-fibre field-emitting source. J. Phys. E. Sci. Instrum. 20, 181-188.
Madanat M A, Mousa M S, A N Al-Rabadi A N, and Fischer A (2015) Electron microscopy-based performance evaluation of various tungsten field-emitter tips Apex radii. Jo. J. Phys. 8, 79-85.

Marrese C M (2000) A review of field emission cathode technologies for electric propulsion systems and instruments. IEEE Aerospace Conference Proceedings, 4, 85-98.

Marulanda J M (2010) Carbon Nanotubes, In: Tech ed. pp. 311-340.

Melmed A J (1991) The art and science and other aspects of making sharp tips. J. Vac. Sci. Tech. B 9, 601-608.

Meza M, Lubin J A C, Villegas Rosales T F, Gutarra Espinoza K A, Martin F, and Cousty J (2015) Fabrication of ultra-sharp tips from carbon fiber for scanning tunneling microscopy investigations of epitaxial graphene on 6H-SiC(0001) surface. Carbon 86, 363-370.

Mousa M S (1996), Electron emission from carbon fiber tips. Appl. Surf. Sci. 94/95, 129-135.

Mousa M S, Al Share M (1999) Study of the MgO-coated W emitters by field emission microscopy. Ultramicroscopy 79, 195-202.

Mousa M S, Brugat M, Sheshin E P, and Hagmann M J (2001) Prototypes using metal, carbon fiber and composite field emission sources modulated by a laser beam. Ultramicroscopy 89, 129-135.

Mousa M S (2007). Influence of a dielectric coating on field electron emission from micro-point electron sources. Surf. Interface Anal. 39, 102-110.

Mousa M S, Fischer A, and Mussa K O (2012), Metallic and composite micropoint cathodes: aging effect and electronic and spatial characteristics. Jo. J. Phys. 5, 21-26.

Winkler J H (1744) Gedanken von den Eigenschaften, Wirkungen und Ursachen der Electrizität nebst Beschreibung Zweier Electrischer Maschinen (Verlag B. Ch.Breitkopf, Leipzig). 